\title{
Agrobacterium-mediated Transformation of Nicotiana tabacum cv. Xanthi Leaf Explants
}

Ana Lilia Rosales-Campos and Abel Gutiérrez-Ortega*

Unidad de Biotecnología Médica y Farmacéutica, Centro de Investigación y Asistencia en Tecnología y Diseño del Estado de Jalisco. Guadalajara, Jalisco, México

*For correspondence: aortega@ciatej.mx

[Abstract] Plant transformation has become an important technology for the large-scale production of a number of goods, ranging from vaccines and pharmaceutical products to biofuel. A plant that is frequently used for this purpose is Nicotiana tabacum due to several advantages: it can be easily regenerated, its genome is completely sequenced and genetic transformation is straightforward. We describe here the most common method for tobacco genetic transformation, which involves Agrobacterium tumefaciens. Many plasmid vectors are compatible with this bacterium, allowing the transformation of a wide range of plant species, as well as the insertion of more than two genes of interest in the plant genome. Furthermore, the capability to transfer a single copy DNA fragment to its host reduces the probability to switch off the gene or genes of interest. Here, we present a simple and reliable methodology to transform tobacco leaf explants using Agrobacterium tumefaciens to insert two genes of interest.

Keywords: Agrobacterium tumefaciens, Genetic transformation, In vitro culture

[Background] Plants have been exploited as expression bioreactors for vaccine antigens, antibodies for immunotherapy, nutritional supplements, enzymes, and even peptides of interest with industrial applications (Sharma and Sharma, 2009). They require relatively low financial investment to conduct initial studies, constituting a large advantage for biotechnology entrepreneurs (Yao et al., 2015). After the first plant transformation reports (Fraley et al., 1983; Herrera-Estrella et al., 1983), protocols have not changed a lot using Agrobacteria as a method for this purpose; nevertheless, other methods have been developed to enhance transformation efficiency, such as biolistics. Currently, tobacco is among the most important plant platforms for protein expression; its cells, as other eukaryotic cells, can perform post-translational modifications to the proteins of interest and tobacco plants can be easily regenerated by organogenesis or embryogenesis; additionally, its genome is completely sequenced. Current protocols allow for the insertion of multiple transgenes, requiring only one selectable marker (Wang, 2015). Our protocol is based on Curtis et al. (1995) and involves co-cultivation Agrobacterium-Nicotiana tabacum, like another protocol with algae (Pratheesh et al., 2014) or fungi. We were able to transform Nicotiana tabacum with a binary plasmid that contained two expression cassettes for the simultaneous expression of two viral antigens and confirmed that both genes were expressed by RT-PCR analysis in transformed plants. 


\section{Materials and reagents}

1. $15 \mathrm{ml}$ centrifuge tubes

2. Plastic pots (Home depot, catalog number: 504092)

3. Scalpel

4. Parafilm

5. Aluminum foil

6. Disposable plastic Petri plates

7. Electroporation cuvettes $0.2 \mathrm{~cm}$ (Bio-Rad, catalog number: 1652086)

8. Plastic vessels for plant tissue culture, $1 \mathrm{~L}$ (Sigma-Aldrich, catalog number: B8648)

9. Vessel for plant tissue culture, $100 \mathrm{ml}$ (Sigma-Aldrich, catalog number: V8630)

10. Tobacco seeds cv. Xanthi

11. Agrobacterium tumefaciens strain LBA4404

12. pCAS35S plasmid vector

13. Binary plasmid vector pCAMBIA2300gp5-m

14. Murashige and Skoog basal medium w/vitamins (PhytoTechnology Laboratories, catalog number: M519)

15. Distilled water

16. Cefotaxime (Sigma-Aldrich, catalog number: C7039)

17. Kanamycin (Thermo Fisher, catalog number: 11815024)

18. Acetosyringone (3'5'Dimethoxy-4'hydroxyacetophenone) (Sigma-Aldrich, catalog number: D134406)

19. YM medium broth (Amresco, catalog number: J904)

20. Agar (Difco, catalog number: 281230)

21. $1 \mathrm{~N} \mathrm{NaOH}$

22. $1 \mathrm{~N} \mathrm{HCl}$

23. $96 \%$ ethanol

24. Methanol

25. Sodium hypochlorite (household bleach 6\%)

26. Phytagel (Sigma-Aldrich, catalog number: P8169)

27. Sucrose (Sigma-Aldrich, catalog number: S5391)

28. Glycerol

29. Benzyl aminopurine (BAP) (Sigma-Aldrich, catalog number: B3408)

30. Benzyl aminopurine (BAP) stock $(1 \mathrm{mg} / \mathrm{ml}$ ) (see Recipes)

31. Acetosyringone $100 \mathrm{mM}$ (see Recipes)

32. MS basal medium (see Recipes)

33. MS co-cultivation medium (see Recipes)

34. MS selection medium (see Recipes)

35 . MS rooting medium (see Recipes) 


\section{Equipment}

1. Micropipettes

2. $250 \mathrm{ml}$ flasks

3. Glass containers

4. Curved and straight tweezers

5. $\mathrm{pH}$ meter (Bante 210)

6. Orbital mixer

7. Analytical balance (A\&D, catalog number: 11100-80)

8. Autoclave

9. Vortex

10. Gene pulser II electroporator (Bio-Rad)

11. Laminar flow hood

12. Growth chamber $24^{\circ} \mathrm{C}$ with $12 / 12 \mathrm{~h}$ photoperiod

13. Greenhouse

\section{Procedure}

A. Agrobacterium tumefaciens transformation with plasmid vector

1. To generate two expression cassettes, we amplified the genes of interest and added Ncol and Sstl restriction sites by PCR to clone them by separate into pCAS35S plasmid vector. This vector has as a double 35S promoter, a TEV 5 ' leader sequence and a 3' VSP polyadenylation signal (p35S, Gutiérrez-Ortega et al., 2005).

2. Both expression cassettes were sequentially cloned into binary plasmid pCAMBIA2300 with HindIII and EcoRI restriction enzymes.

3. Electroporate A. tumefaciens LBA4404 competent cells (grow a single colony of $A$. tumefaciens in $3 \mathrm{ml} \mathrm{YM}$ liquid medium for $24 \mathrm{~h}$ at $30^{\circ} \mathrm{C}$ and $200 \mathrm{rpm}$, inoculate $100 \mathrm{ml}$ of YM liquid media with $100 \mu \mathrm{l}$ of pre-inoculum and incubate for $12 \mathrm{~h}$ at the same settings, wash cells twice with deionized water and store them at $-80{ }^{\circ} \mathrm{C}$ for up to six months in $10 \%$ glycerol) with plasmid pCAMBIA2300gp5-m as follows: place $50 \mu \mathrm{l}$ of electrocompetent cells inside a $0.2 \mathrm{~cm}$ gap electroporation cuvette along with $0.5 \mu \mathrm{l}$ of plasmid pCAMBIA2300gp5-m and pulse with the following parameters: $200 \Omega, 25 \mu \mathrm{F}$ and $2.5 \mathrm{kV}$.

4. Recover electroporated cells in $500 \mu \mathrm{YM}$ medium for $3 \mathrm{~h}$ at $30^{\circ} \mathrm{C}$.

5. Plate $100 \mu \mathrm{l}$ of cells in $\mathrm{YM}$ with $50 \mathrm{mg} / \mathrm{L}$ kanamycin and incubate for $48 \mathrm{~h}$ at $30{ }^{\circ} \mathrm{C}$.

B. Containers

1. Prepare five $100 \mathrm{ml}$ and twelve $1 \mathrm{~L}$ vessels with $\mathrm{MS}$ basal medium. The number of $1 \mathrm{~L}$ vessels depends on the number of plants that germinated, so this is a very rough estimation. 
2. Prepare 40 Petri plates with MS co-cultivation medium, 40 Petri plates with MS selection medium and twenty $100 \mathrm{ml}$, twenty $1 \mathrm{~L}$ vessels with rooting medium (see Recipes). These numbers depend on the number of buds per explant, as well as those that survive contamination, for the selection stage, so this is also a rough estimation. In this protocol, we used phytagel instead of agar.

C. Tobacco seed germination and growth

1. Under sterile conditions, inside a laminar flow hood, pour seeds into a microcentrifuge tube until the $100 \mu \mathrm{l}$ mark, add $1 \mathrm{ml}$ of $70 \%$ alcohol with a micropipette and mix thoroughly by inverting the tube for $2 \mathrm{~min}$.

2. Discard alcohol by pipetting, wash by adding $1 \mathrm{ml}$ of distilled water with micropipette, mix gently and discard supernatant.

3. Add $1 \mathrm{ml}$ of household bleach and mix thoroughly for $3 \mathrm{~min}$ by inversion, discard bleach and wash twice with $1 \mathrm{ml}$ of distilled water.

4. Set around twelve seeds on the surface of $100 \mathrm{ml}$ vessels with $35 \mathrm{ml}$ of MS basal medium by pipetting.

5. Place seeded vessels inside a growth chamber until plantlets have distinguishable hairy roots (3 weeks).

6. Inside a laminar flow hood, transfer plantlets into $1 \mathrm{~L}$ vessels containing MS basal medium with tweezers, until having mature plants (2 more weeks).

D. Growth of Agrobacterium harboring the binary plasmid

1. Grow Agrobacterium tumefaciens strain LBA4404 with the plasmid of interest in YM medium plates for $48 \mathrm{~h}$ at $30^{\circ} \mathrm{C}$.

2. Pick a single colony of Agrobacterium tumefaciens and inoculate $3 \mathrm{ml}$ of $\mathrm{YM}$ liquid medium supplemented with $50 \mathrm{mg} / \mathrm{L}$ kanamycin and grow overnight at $30{ }^{\circ} \mathrm{C}$ in an orbital mixer at $200 \mathrm{rpm}$.

3. Inoculate $50 \mathrm{ml}$ of $\mathrm{YM}$ medium supplemented with $50 \mathrm{mg} / \mathrm{L}$ kanamycin and $200 \mu \mathrm{M}$ acetosyringone with $50 \mu \mathrm{l}$ of pre-inoculum and grow the culture overnight at $30^{\circ} \mathrm{C}, 200 \mathrm{rpm}$.

\section{E. Explants obtainment}

1. Inside a laminar flow hood, select healthy tobacco leaves, cut them at the petiole with scalpel and transfer them with tweezers in a sterile disposable Petri plate.

2. Remove the petiole, midrib and borders from the leaf, and trim it into $1 \mathrm{~cm}^{2}$ squared explants, as shown in Figure 1. 


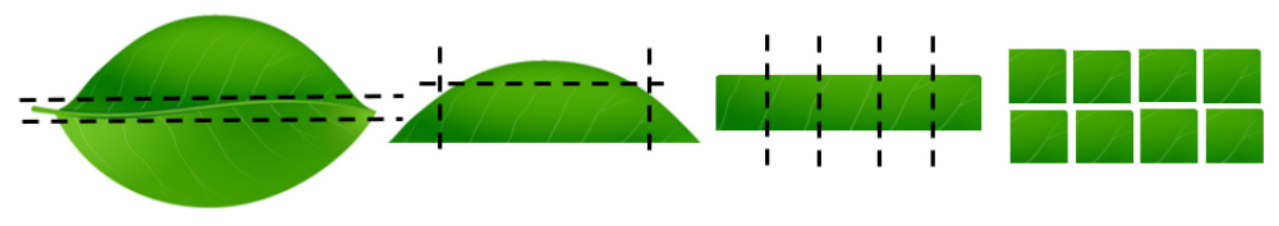

Figure 1. Explants of tobacco plants. Keep the explants in a Petri plate with deionized water in order to avoid dehydration before transformation. Explants need to be used within the next 30 min for transformation.

F. Tobacco transformation

1. Transfer explants into a new Petri plate and add the media with Agrobacterium tumefaciens until the explants are covered with the liquid approximately $35 \mathrm{ml}$, mix gently by hand or with an orbital mixer (inside a laminar flow hood) for 5 min.

2. Take the explants one by one with tweezers and drain excess liquid.

3. Place explants in Petri plates with MS co-cultivation medium with the abaxial side up, 10 to 12 explants per Petri plate, cover and seal with parafilm.

4. Cover the Petri plates from light with aluminum foil and keep them in the dark for $48 \mathrm{~h}$ at $18{ }^{\circ} \mathrm{C}$ to $24{ }^{\circ} \mathrm{C}$ for cocultivation.

5. Transfer the explants with adaxial side up to MS selection medium as shown in Figure 2, grow for 2 weeks in a growth chamber at $24{ }^{\circ} \mathrm{C}$ with $12 / 12 \mathrm{~h}$ photoperiod; regenerated shoots would have developed during this period.

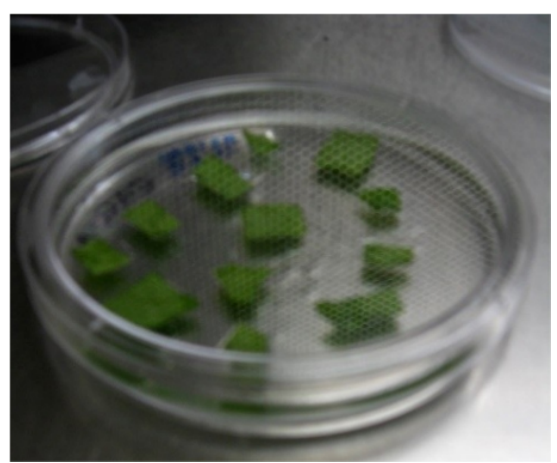

Figure 2. Tobacco explants in MS selection medium

6. Transfer regenerated shoots into $100 \mathrm{ml}$ vessels with MS rooting medium, for root formation. Only three to four shoots should be placed per vessel as shown in Figure 3; plantlets will need enough space and nutrients to grow.

7. Transfer transformed and fully regenerated plantlets into $1 \mathrm{~L}$ vessels with MS rooting medium. 

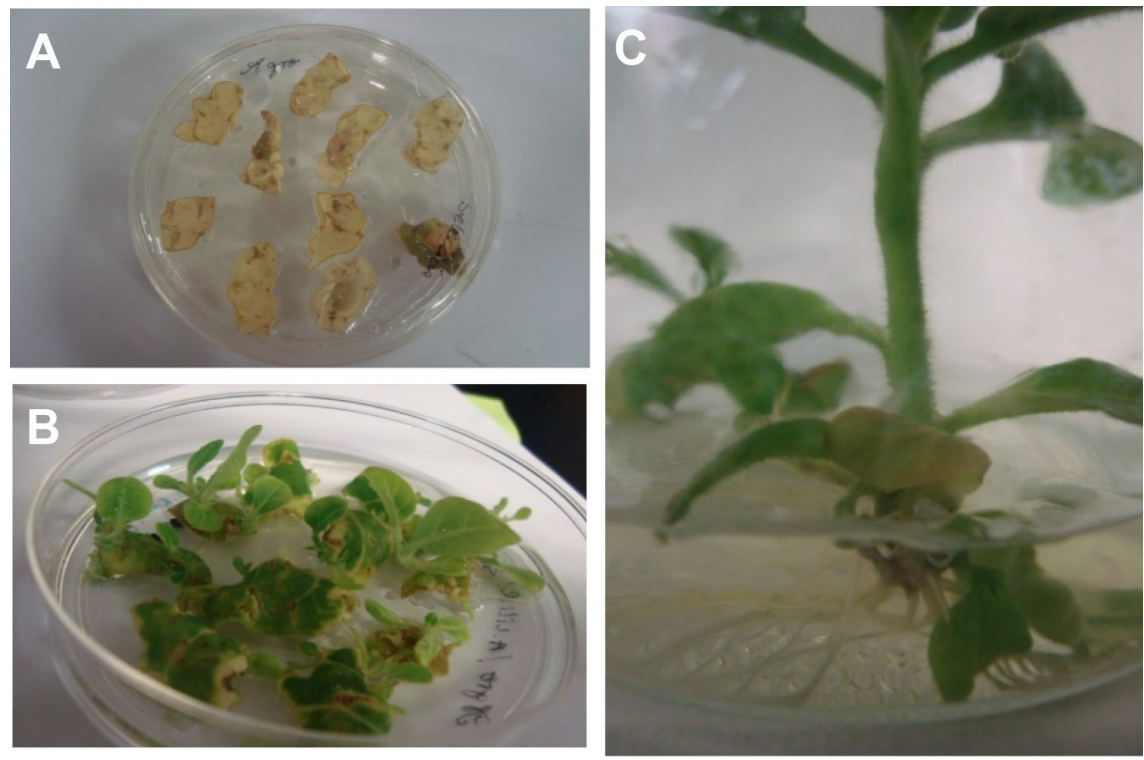

Figure 3. Tobacco explants in MS selection medium and regenerated plantlet in MS rooting medium. A. Explants cocultivated with untransformed Agrobacterium tumefaciens strain. B. Explants cocultivated with Agrobacterium tumefaciens strain that harbors the binary plasmid. C. Regenerated tobacco plant transformed with Agrobacterium tumefaciens strain that harbors the binary plasmid.

8. When the plants are ready for ex vitro adaptation, open the containers, remove plants carefully from the vessel, rinse thoroughly the plant roots with tap water to eliminate the remaining medium, and place the plants into a pot with wet substrate (roots should be perfectly buried into the substrate). Afterwards, cover the pot with a plastic bag for 1 week until the tobacco plants are adapted to the new substrate, at this stage plants should be turgid (Figure 4). Discard the plastic bag and keep growing the plant until they set seeds.
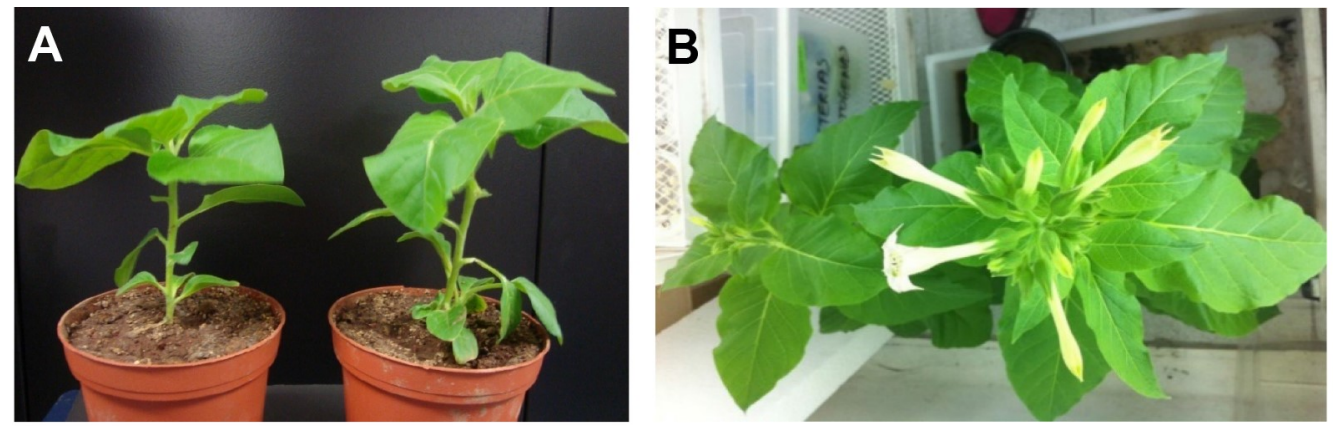

Figure 4. Tobacco plants after ex vitro adaptation. A. Tobacco plants 3 weeks after transfer to pots. B. Tobacco plants 6 weeks after transfer to pots. 


\section{$\underline{\text { Recipes }}$}

1. Benzyl aminopurine (BAP) stock $(1 \mathrm{mg} / \mathrm{ml})$

Weigh $10 \mathrm{mg}$ of BAP

Dissolve in $1 \mathrm{ml} 1 \mathrm{~N} \mathrm{NaOH}$ and make up to $10 \mathrm{ml}$ with distilled water

2. Acetosyringone $100 \mathrm{mM}$

Weigh $0.196 \mathrm{~g}$ of acetosyringone

Dissolve in $1 \mathrm{ml}$ methanol and make up to $10 \mathrm{ml}$ with distilled water, sterilize by filtration and store at $-20^{\circ} \mathrm{C}$

3. MS basal medium (100 $\mathrm{ml}$ and $1 \mathrm{~L}$ vessels)

Murashige and Skoog with vitamin salts $4.42 \mathrm{~g}$

Sucrose $\left(\mathrm{C}_{12} \mathrm{H}_{22} \mathrm{O}_{11}\right) 30 \mathrm{~g}$

Phytagel $2.5 \mathrm{~g}$

a. Dissolve all of the previous reagents except phytagel in $800 \mathrm{ml}$ distilled water, adjust $\mathrm{pH}$ to 5.8 , and then add phytagel powder and make up to $1 \mathrm{~L}$ with distilled water

b. Autoclave at $21^{\circ} \mathrm{C}$ for $15 \mathrm{~min}$

4. MS rooting medium $(100 \mathrm{ml}$ and $1 \mathrm{~L})$

Murashige and Skoog with vitamin salts $4.42 \mathrm{~g}$

Sucrose $\left(\mathrm{C}_{12} \mathrm{H}_{22} \mathrm{O}_{11}\right) 30 \mathrm{~g}$

Phytagel $2.5 \mathrm{~g}$

Kanamycin $100 \mathrm{mg} / \mathrm{L}$

Cefotaxime $500 \mathrm{mg} / \mathrm{L}$

a. Dissolve all of the previous reagents except phytagel and antibiotics in $800 \mathrm{ml}$ distilled water, adjust $\mathrm{pH}$ to 5.8 , and then add phytagel powder and make up to $1 \mathrm{~L}$ with distilled water

b. Autoclave at $121^{\circ} \mathrm{C}$ for $15 \mathrm{~min}$, after that add antibiotics under sterile conditions

5. MS co-cultivation medium (Petri plates)

Murashige and Skoog with vitamin salts $4.42 \mathrm{~g}$

Sucrose $\left(\mathrm{C}_{12} \mathrm{H}_{22} \mathrm{O}_{11}\right) 30 \mathrm{~g}$

Benzyl aminopurine $0.5 \mathrm{mg} / \mathrm{L}$

Phytagel $2.5 \mathrm{~g}$

a. Dissolve all of the previous reagents except phytagel in $800 \mathrm{ml}$ distilled water, adjust $\mathrm{pH}$ to 5.8 , and then add phytagel powder and make up to $1 \mathrm{~L}$ with distilled water

b. Autoclave at $121^{\circ} \mathrm{C}$ for $15 \mathrm{~min}$

c. After that add benzyl aminopurine under sterile conditions

6. MS selection medium (Petri plates)

Murashige and Skoog with vitamin salts $4.42 \mathrm{~g}$

Sucrose $\left(\mathrm{C}_{12} \mathrm{H}_{22} \mathrm{O}_{11}\right) 30 \mathrm{~g}$

Phytagel $2.5 \mathrm{~g}$

Benzyl aminopurine $0.5 \mathrm{mg} / \mathrm{L}$ 
Kanamycin $100 \mathrm{mg} / \mathrm{L}$

Cefotaxime $500 \mathrm{mg} / \mathrm{L}$

a. Dissolve all of the previous reagents except phytagel, benzyl aminopurine, kanamycin and cefotaxime in $800 \mathrm{ml}$ distilled water, adjust $\mathrm{pH}$ to 5.8 , and then add phytagel powder and make up to $1 \mathrm{~L}$ with distilled water

b. Autoclave at $121^{\circ} \mathrm{C}$ for $15 \mathrm{~min}$

c. After that, add antibiotics and benzyl aminopurine under sterile conditions

\section{Acknowledgments}

This work was supported by SEP-CONACYT grant number 83863. Also, I would like to thank Ph.D. Asdrúbal Burgos for critical review of this manuscript. Authors declare that they have no conflicts of interest.

\section{$\underline{\text { References }}$}

1. Curtis, I., Davery, M. and Power, J. (1995). Leaf disk transformation. Methods Mol Biol 44: 5970.

2. Fraley, R. T., Rogers, S. G., Horsch, R. B., Sanders, P. R., Flick, J. S., Adams, S. P., Bittner, M. L., Brand, L. A., Fink, C. L., Fry, J. S., Galluppi, G. R., Goldberg, S. B., Hoffmann, N. L. and Woo, S. C. (1983). Expression of bacterial genes in plant cells. Proc Natl Acad Sci U S A 80(15): 4803-4807.

3. Gutierrez-Ortega, A., Sandoval-Montes, C., de Olivera-Flores, T. J., Santos-Argumedo, L. and Gomez-Lim, M. A. (2005). Expression of functional interleukin-12 from mouse in transgenic tomato plants. Transgenic Res 14(6): 877-885.

4. Herrera-Estrella, L., Depicker, A., Van Montagu, M. and Schell, J. (1983). Expression of chimaeric genes transferred into plant cells using a Ti-plasmid-derived vector. Nature 303(5914): 209-213.

5. Pratheesh, P. T., Vineetha, M. and Kurup, G. M. (2014). An efficient protocol for the Agrobacterium-mediated genetic transformation of microalga Chlamydomonas reinhardtii. Mol Biotechnol 56(6): 507-515.

6. Sharma, A. K. and Sharma, M. K. (2009). Plants as bioreactors: Recent developments and emerging opportunities. Biotechnol Adv 27(6): 811-832.

7. Wang, K. (2015). Preface. Agrobacterium protocols. Methods Mol Biol 1224: vii-viii.

8. Yao, J., Weng, Y., Dickey, A. and Wang, K. Y. (2015). Plants as factories for human pharmaceuticals: applications and challenges. Int J Mol Sci 16(12): 28549-28565. 